\title{
Taking stock of decentralized disaster risk reduction in Indonesia
}

\author{
Anthony Grady ${ }^{1}$, Berry Gersonius ${ }^{2}$, and Alexandros Makarigakis ${ }^{1}$ \\ ${ }^{1}$ Section on Earth Sciences and Geo-Hazards Risk Reduction, Natural Sciences Sector, UNESCO, Paris, France \\ ${ }^{2}$ UNESCO-IHE, Delft, the Netherlands
}

Correspondence to: Anthony Grady (anthonygrady4@gmail.com)

Received: 8 June 2015 - Published in Nat. Hazards Earth Syst. Sci. Discuss.: 8 September 2015

Revised: 14 July 2016 - Accepted: 17 July 2016 - Published: 27 September 2016

\begin{abstract}
The Sendai Framework, which outlines the global course on disaster risk reduction until 2030, places strong importance on the role of local government in disaster risk reduction. An aim of decentralization is to increase the influence and authority of local government in decision making. Yet, there is limited empirical evidence of the extent, character and effects of decentralization in current disaster risk reduction implementation, and of the barriers that are most critical to this. This paper evaluates decentralization in relation to disaster risk reduction in Indonesia, chosen for its recent actions to decentralize governance of DRR coupled with a high level of disaster risk. An analytical framework was developed to evaluate the various dimensions of decentralized disaster risk reduction, which necessitated the use of a desk study, semi-structured interviews and a gap analysis. Key barriers to implementation in Indonesia included: capacity gaps at lower institutional levels, low compliance with legislation, disconnected policies, issues in communication and coordination and inadequate resourcing. However, any of these barriers are not unique to disaster risk reduction, and similar barriers have been observed for decentralization in other developing countries in other public sectors.
\end{abstract}

\section{Introduction}

Disaster risk reduction (DRR) focuses on long-term risk reduction by addressing the causal factors of risk in terms of the occurrence of natural hazards, the exposure to natural hazards and the vulnerability of communities (UNDP, 2007). DRR activities aim to reduce the likelihood of a natural hazard occurring, to avoid the exposure of communities or to strengthen community resilience (AusAID, 2016). Community resilience is the ability of a system, community or society exposed to natural hazards to resist, absorb, accommodate and recover from the effects of a hazard in a timely and efficient manner, including through the preservation and restoration of its essential basic structures and functions (UNISDR, 2009). Disaster risk management (DRM) involves activities to prevent, reduce or transfer the adverse effects of hazards through prevention, mitigation and preparedness (IOM, 2009). DRM and DRR activities are complementary in their nature however there are key differences. DRR has a longer term impact, while DRM has a more immediate impact. Furthermore, DRR is more far reaching in addressing vulnerability and has a stronger link with developmental objectives (IOM, 2009).

There is increasing recognition of the importance of good governance as a key factor that enables DRR. For example, the Global Assessment Report on DRR (UNISDR, 2011) points to poor governance as a key underlying driver of disaster risk. Good governance is defined as being participatory, consensus oriented, accountable, transparent, responsive, effective and efficient, equitable and inclusive and following of the rule of law (UNESCAP, 2009). Poor governance results from the absence or a deficiency in the above characteristics (UNESCAP, 2009). Good governance also promotes collaboration across all levels of authority and participation of local communities. Walker et al. (2014) characterise good governance by the emergence of multi-level governance processes, the movement away from the exercise of centralized authority towards the involvement and collaboration of a multiplicity of actors, the creation of new forms of authority, and changing distributions of responsibilities between the state and other actors. The focus of this paper is on decentralization, which is one of the principles of good governance in relation to DRR. 
Decentralization refers to the restructuring of authority so that there is a system of co-responsibility between institutions at the central, regional and local levels according to the principle of subsidiarity (UNDP, 2004). The principle of subsidiarity states that responsibilities and resources should be decentralized down to the lowest level that can effectively perform the tasks involved. This interpretation thus recognizes that decentralization is not a substitute for central government, but instead it creates a continuum of governance from the centre to the local. In other terms, it supports the development of multi-level governance processes (Hooghe and Marks, 2001).

Having in place governance structures at decentralized levels of authority is essential for DRR, since local authorities and local communities are usually the first responders during disasters. Governance of DRR must be at the level appropriate for the type of natural hazard addressed, e.g. river flood risk management should be governed on the river basin scale. Lower levels of authority must, furthermore, be coordinated and facilitated by DRR governance at higher levels. The central role of regional and local authorities in DRR is recognized in the Incheon Declaration (UNISDR, 2009). Also, the Hyogo Framework for Action identified the need for the decentralization of responsibilities and resources for DRR to lower levels of authority (UNISDR, 2005). Its successor, the Sendai Framework for DRR, places even stronger emphasis on decentralization, by incorporating the need to empower local authorities and local communities (through e.g. resources, incentives and decision-making responsibilities) as a principle to guide its implementation (UNISDR, 2015).

There is limited scientific literature concerning decentralization in relation to DRR. Research does concur with the Sendai Framework that theoretically, decentralization is needed for good governance of DRR (Scott and Tarazona, 2011; Bollin, 2003); though the empirical evidence to support this is confined to a few case studies. Scott and Tarazona (2011) found that limited local level capacities can be a constraint to decentralized governance for DRR. Similarly, Djalante et al. (2011) noted a key obstacle concerns how local levels are to be equipped with the skills and resources needed. It was also found that decentralization does not necessarily lead to enhanced participation due to low levels of awareness for DRR and other more pressing priorities (Scott and Tarazona, 2011). In Bangladesh, the decentralization of disaster risk management agencies has been found to increase local ownership for DRR in communities and the accountability of authorities (UNISDR, 2010). Decentralizing DRR offices in the Philippines enhanced mainstreaming of DRR into provincial plans and programmes, though significant challenges remain in the governance of DRR (UNISDR, 2010).

With these mixed results in mind, this paper aims to identify the following: (1) how decentralization of DRR is being implemented currently and (2) which barriers are most crit- ical to implementation. These research questions are examined through the case study of Indonesia, which was chosen due to the country's recent actions to decentralize governance of DRR and the country's high level of disaster risk. Indonesia is one of the top 10 countries at risk according to the Disaster Risk Index, which assesses the exposure and vulnerability of countries towards natural hazards (Peduzzi, 2006). The country is prone to a multitude of natural hazards, including earthquakes, tsunamis, volcanic eruptions, floods, droughts and forest fires due to its sensitive geographic and geological characteristics. The implementation of decentralized DRR in Indonesia is evaluated using the $3 \mathrm{As}$ and $\mathrm{G}$ analytical framework, which addresses the following dimensions: awareness, avoidance, alleviation and governance from the Scottish 4As framework (Ashley et al., 2011). This facilitates an understanding of how decentralized DRR is implemented currently. The key barriers to implementation are deduced as part of this evaluation. Parallels are drawn with the experiences of other developing and transitioning countries (in other sectors, such as health services and education) in this discussion. Lastly, some concluding statements are provided on decentralization of DRR.

The scope of this paper is to consider decentralization for DRR through government structures or structures where government is involved e.g. multi-stakeholder platforms (MSPs). The roles of other actors such as NGOs or international organizations are indeed very important however they are not addressed directly within the scope of this study.

\section{Methodology}

\subsection{Analytical framework}

There are a wide range of frameworks available that may be used to guide the best way to manage disaster risk. These include, but are not limited to the Scottish 4As (awareness, avoidance, alleviation and assistance), the Dutch 4 Capacities (threshold capacity, coping capacity, recovery capacity and adaptive capacity) and the EU Floods Directive 3Ps (prevention, preparedness and preparation) (Ashley et al., 2011). In this paper, the "4As" framework for flood risk management is adopted, as it is puts greater emphasis on the role of local authorities and local communities through its four dimensions (which is evident from the definitions provided below). This framework was subsequently modified to address DRR in particular and to also include the governance of disaster risk. As such, it was considered appropriate to indirectly address assistance (the fourth A in "4As"), as this dimension primarily concerns those activities that are carried out during and after the disaster event (not part of DRR). Furthermore, disaster risk governance has been included as a separate dimension, which specifically addresses the institutional, legal and financing system in relation to DRR (planning element). This is an overarching dimension that links to the three other 


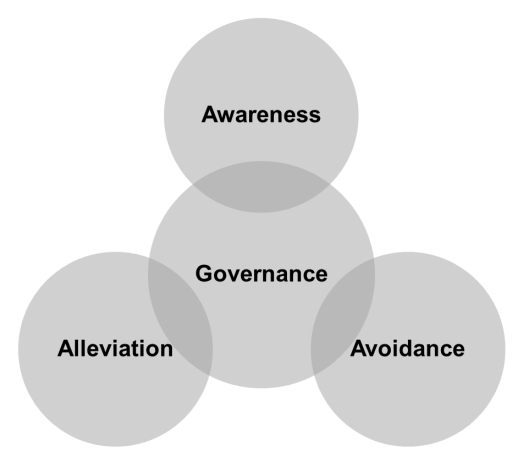

Figure 1. 3As \& G evaluation framework adopted in research.

dimensions. The updated framework is presented in Fig. 1, which is referred to as the $3 \mathrm{As} \& \mathrm{G}$ framework in the remainder of the paper. The $3 A s \& G$ framework is used to evaluate the extent, character and effects of decentralization in DRR in Indonesia in a holistic manner.

The dimensions of the $3 \mathrm{As} \& \mathrm{G}$ framework are taken to mean the following:

- disaster risk awareness - enhancing the awareness and engagement in all aspects of disaster risk and the means (e.g. tools, strategies and networks) of managing awareness at the policy level (politicians/decision makers), among the professionals (of the involved authorities and elsewhere) and at the public level (individuals, companies, developers, insurance companies).

- disaster risk avoidance - avoiding exposure if possible, limiting damage and easing recovery by planning and adapting buildings, infrastructure, surfaces as well as economic activities and building capacity in authorities and communities to become more resilient.

- disaster risk alleviation - containing the hazardous event, and therefore reducing disaster risk by implementing physical, technical, non-structural and procedural measures for the management of natural systems.

- disaster risk governance - re-organizing the institutional structures and policy processes that guide and restrain the collective activities of authorities and communities to reduce disaster risk (Renn et al., 2011). This includes considerations of the institutional, legal and economic contexts in which decisions about risks are taken and implemented.

\subsection{Data collection and analysis}

To answer research question one and research question two, the following research methods were employed: desk study, on-site interviews and gap analysis.

To understand how decentralization is being implemented currently, secondary data in the form of academic, profes- sional and government publications were used in conducting the desk study. This study facilitated the mapping of the institutions involved in DRR in Indonesia, together with the legal and policy context. These mapping activities were fundamental to understanding the mechanics of governance and the extent and role of decentralization.

A field investigation was undertaken to Indonesia to better understand how the DRR framework is being implemented currently and to deduce the barriers that are critical to implementation.

A total of 28 people were interviewed following consultation with practitioners on the ground and desk research to identify key relevant actors. The interviewees were from a variety of international organizations, civil society organizations (CSOs), non-governmental organizations (NGOs), development agencies, governmental agencies and ministries, and universities and research institutions. Semi-structured interviews were conducted given the diverse areas of expertise of the interviewees and to facilitate interviewee input of their own opinions and recommendations.

The people interviewed were from organizations which were part of or worked with the Indonesian government at national, provincial (Special Capital Region of Jakarta, Special Province of Yogyakarta and West Sumatra), and city/district (Padang City, Yogyakarta City, Central Jakarta, South Jakarta) levels. The DRR government structures in these eight administrative areas were case studies for this research. They were selected following the desk study review and upon expert interviewee recommendation as they have made relative progress in adopting a decentralized government of DRR. The selection of these case studies also provided a complete vertical view engaging constituent governments at the various levels of authority. Details of the organizations with whom interviews are cited are provided in Sect. A1.

The research methods detailed above underpinned the development of the $3 \mathrm{As} \& \mathrm{G}$ framework. It was necessary to deduce parameters for each dimension of the applied framework to provide a view of the current state of decentralized DRR in Indonesia. These parameters are tools, strategies and networks that are indicators of the particular dimension. The parameters of the Disaster Risk Awareness and Disaster Governance dimensions were deduced from the desktop study (Batica, 2005; IFRC, 2011; UNESCAP, 2009). The parameters of the Disaster Risk Alleviation and Disaster Risk Avoidance dimensions were deduced following consultation with DRR practitioners (UNESCO Jakarta, interview, 2013; UNDP Jakarta, interview, 2013). The finalized list of parameters was then validated by DRR practitioners (UNESCO Jakarta, interview, 2013; UNDP Jakarta, interview, 2013) to ensure all elements key to realizing DRR were included in the framework.

A gap analysis, as defined by Gomm (2009), is "the space between where we are and where we want to be, and serves as a means to bridge that space." A gap analysis was em- 
ployed to determine the current status of decentralized DRR in Indonesia, to determine a baseline for the ideal state of the decentralized DRR and to identify gaps between the current and ideal state (barriers to implementation).

UNESCAP (2009) defines good governance as being participatory, consensus oriented, accountable, transparent, responsive, effective and efficient, equitable and inclusive and following of the rule of law. This formed the theoretical basis for deducing the ideal state which was a collation of good practice characteristics of decentralized DRR. These characteristics were gathered using the desk study and interview research methods. They were discerned from decentralization theory in additional to examples of successful decentralization in DRR and other public sectors. The criteria for these good governance practices are closely aligned to development at large in that they build resilient communities with actors at all levels involved in decision-making processes for planning and delivery of key goods and services (UNDP, 2010). This ideal state is presented in Sect. 4.5.

\section{Decentralization in relation to DRR in Indonesia}

\subsection{Decentralization processes in Indonesia}

The Indonesian government is organized into six levels of authority, from the national level to the local community level. The decentralized system of government is still taking root in Indonesia. The former 280 district-level governments had increased to about 500 by mid-2010 (Lassa, 2010). Given that it commonly takes from 3 to 10 years to complete the transition to decentralized government (Lassa, 2010), there are many district-level governments which have not yet developed to full capacity to conduct their specified tasks. Figure 2 maps how DRR is being managed by the Indonesian government at the levels of authority to the city/district level. This illustration depicts the head of government, government institutions and the MSP's that function at the respective levels of administration. The MSPs are shown given their key role in open and collaborative governance.

The cross cutting nature of DRR requires the involvement of all line ministries. As noted by Datta et al. (2011), decentralization has limited the influence of the line ministries. The researchers observed that line ministries generally now function in terms of facilitators and must negotiate with lower levels of authority on the structure and implementation of programmes.

The activities of the line ministries are coordinated by BNPB (National Disaster Management Agency), which is a dedicated agency for DRR at the national level. BNPB is a non-ministerial agency, which is equal in level with the line ministries. It provides direction and guidelines on all elements of DRR, and it reports to the President once per month under normal conditions. The agency also coordinates and leads the emergency response during and post disasters.

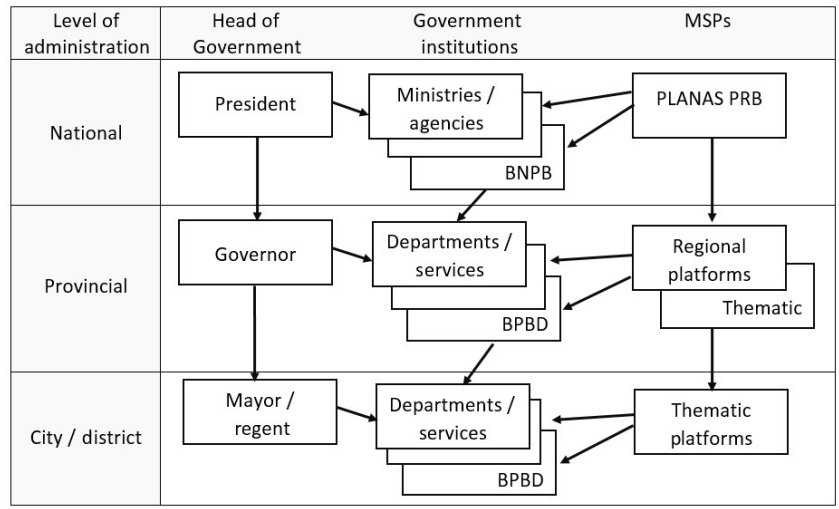

Figure 2. Institutional structure for DRR in Indonesia (adapted from COE-DMHA, 2011).

It receives its funding from the national annual government budget (APBN) (Indonesia, 2008).

BPBDs are the dedicated agencies for DRR at the provincial and district levels. These agencies coordinate DRR activities of other government agencies (at the provincial and district level) and implement DRR programmes in their territories. They also provide guidance and direction to local governments and on DRR-related issues. BPBDs are independent of BNPB and are, in theory, funded through the provincial or district-level annual budgets, though many are actually reliant on allocations from central government (provincial BPBD West Sumatra, interview, 2013).

\subsection{Impact of decentralization on DRR}

Decentralization in Indonesia has left the provincial level with limited power. The lack of policy influence and financial control on lower levels of authority means that the provincial government does not have the authority needed to effectively realise its task of monitoring and evaluating DRR (UNDP, 2009). This "missing link" of provincial government implies that DRR policy cannot be filtered from national level through the provincial level to the local level of authority, and vice versa. The 2014 Law on Local Government aimed to address these challenges concerning provincial decentralization. It will be some time before the consequences of this new law on decentralization are known. Note that the provinces of Aceh, Jakarta and Yogyakarta have greater autonomy in decentralization than other provinces. There is variation in the powers between these three provinces (Kurniadi, 2009).

In contrast, the district level of authority now has significant power - being the focal point of decentralization in Indonesia due to concerns of national disintegration (e.g. separation of provinces such as Aceh) (UNDP, 2009). Yet, fiscal autonomy of new cities/districts presents a significant obstacle to decentralized DRR. It has been noted that less than $5 \%$ of these governments can fund their annual budgets and they have to rely upon central government for support (Lassa, 
2010). This dependence means the district level has proper regard for the national government; however, there is limited regard for the provincial governments (UNDP, 2009).

Next to the government, there is also a number of multistakeholder platforms (MSPs) involved in the management of DRR. A MSP is interpreted by Djalante (2012) as "a multiplicity of organisations at different scales of governance working towards more coordinated and integrated actions in DRR". The role of a MSP commonly involves the coordination amongst multitudes of organizations. These platforms are informal DRR agencies, often established as pilot projects by international NGOs and international organizations. It is noted that MSPs have less influence on the planning and implementation of DRR activities than formal DRR agencies, such as BNPB and BPBDs. Only those MSPs that are able to generate funding have the capacity to directly implement DRR activities (Djalante, 2012).

PLANAS PRB is the national level platform for DRR in Indonesia. It is a MSP with stakeholders representing the government, civil society, academia, the media, the private sector and the international community. PLANAS PRB advocates on DRR by providing a mechanism for stakeholders to lobby for DRR issues at different levels through a single entity.

Regional MSPs have been established in the most disasterprone areas of Indonesia, namely Aceh, Padang and Yogyakarta (Djalante, 2012). Furthermore, thematic MSPs address particular DRR issues, such as the Consortium for Disaster Education (CDE) on education, as well as particular hazards, such as Merapi Volcano. Many regional and thematic MSPs were founded following disasters, e.g. following the Yogyakarta earthquake and the Merapi volcanic eruptions (Djalante, 2012). As with the national level platform, regional and thematic MSPs aim to provide advocacy, offer consultancy and influence planning and implementation of DRR activities related to a particular region or theme (incl. hazard).

\section{Results}

The results present the current state of decentralized DRR in Indonesia through the dimensions of the $3 \mathrm{As} \& \mathrm{G}$ analytical framework employed (Sects. 4.1-4.4 below). The results of the gap analysis are then presented. The ideal state is presented in Sect. 4.5 with the barriers for decentralized DRR in Sect. 4.6.

As detailed in Sect. 2.2, parameters were deduced for each dimension of the applied 3As \& $\mathrm{G}$ framework. These parameters and their corresponding framework dimension are provided in Table 1 below. These parameters will be addressed in further detail through their respective dimension in Sects. 4.1-4.4 below.

\subsection{Disaster risk awareness}

The most significant means of managing the awareness and engagement of all actors (including the public) comprise: education, risk assessment and MSPs.

Both formal and informal education on disaster risk is important for raising disaster risk awareness. The general education curriculum is still developed by the central government (ASEAN, interview, 2013). As the result of decentralization, there is some space left for lower levels of authority as well as school governing bodies to add necessary subjects; while all the compulsory subjects are set by the central government. This has facilitated bottom-up movements in Aceh, Padang and Yogyakarta to mainstream DRR into the education curriculum. The inclusion of local content in curricula provides opportunity for location specific DRR to be addressed in education (Dharma, 2008). However, the required capacity for curriculum development has not been decentralized to the lower levels (ASEAN, interview, 2013).

As key tools for communication and collaboration on disaster risk, risk assessments are crucial in building disaster risk awareness. Risk assessments have been conducted for all 33 provinces by BNPB. Moreover, guidelines for conducting risk assessments were published by BNPB in 2012. These guidelines have, however, not been disseminated to all provinces $\left(\mathrm{BNPB}^{1}\right.$, interview, 2013; $\mathrm{BNPB}^{2}$, interview, 2013; Indonesian Institute of Sciences LIPI, interview, 2013); neither has the capacity to conduct risk assessments been built up at the provincial level. In most cases, BNPB has hired consultants to assess the disaster risk, in collaboration with the BPBD. In West Sumatra, this financing arrangement has resulted in limited accountability of the consultant to the BPBD and, therefore, limited engagement (provincial BPBD West Sumatra, interview, 2013). Because of the limited capacity and engagement, there is a low ownership of the risk assessments produced at the provincial level (BPBD Special Province of Yogyakarta, interview, 2013).

Since MSPs are composed of participants from multiple organizations, e.g. government, NGOs, CSOs, academia and the private sector, they can have a key role in raising awareness for DRR. MSPs have been formed at national and subnational level in Indonesia. At national level, PLANAS PRB has been a key player in DRR planning, namely for the NAP-DRR 2010-2012 and the NP DM 2010-2014 (Djalante, 2012). At sub-national level, Merapi Forum has been central to raising awareness, building capacity and improving coordination between stakeholders for the Merapi Volcano. This has been cited as a key reason for the high preparedness among residents of the villages closest to the summit (Wulan Mei et al., 2013). Some regional MSPs have played important roles in DRR planning as well, such as the Yogyakarta Forum (which can be partly explained by the active role of BAPPEDA in this platform). In general, however, the regional MSPs function primarily in administration and have 
Table 1. Relevant parameters for each dimension of DRR.

\begin{tabular}{llll}
\hline Awareness & Avoidance & Alleviation & Governance \\
\hline Education & Spatial planning & Management of natural systems & Institutional system \\
Risk assessment & Building codes & Development planning & Legal system \\
MSPs & Retrofitting and restructuring & & Financing system \\
& Disaster risk infrastructure & & \\
\hline
\end{tabular}

limited influence on DRR planning, implementation and advocacy (Djalante, 2012).

On cross MSP collaboration, members of certain MSPs have become involved in other MSPs at regional level, for example Merapi Forum members (a thematic MSP) have become involved in the Yogyakarta Forum (a regional MSP). It is, furthermore, of note that coordination between PLANAS PRB and the regional MSPs is generally poor (UNDP Jakarta, interview, 2013).

\subsection{Disaster risk avoidance}

The most significant means to avoid exposure of communities and to strengthen community resilience include: spatial planning, building codes, retrofitting and reconstruction and disaster risk infrastructure.

The role of spatial planning in DRR is to avoid locating new development in areas of high disaster risk. There has been a significant lag in enacting spatial planning regulations at sub-national levels, which hampers the implementation of spatial planning as means of disaster risk avoidance (Centre for Volcanology and Geological Hazard Mitigation, interview, 2013). Though the Spatial Planning Law 26/2007 was enacted at national level in 2007, less than $20 \%$ of provinces and only $2 \%$ of districts had passed the regulations at their respective levels by 2010 (Lassa, 2010). Furthermore, hazard maps are not being used optimally in spatial planning at the provincial and district/city level though there may be cases where risk planning has been used in local level planning (Centre for Volcanology and Geological Hazard Mitigation, interview, 2013).

Adherence to building codes contributes to reduced vulnerability and, therefore, increased community resilience. For example, the analysis of the M7.0 September 2009 earthquake demonstrated that had the construction of buildings followed the 2002 building codes, the resulting damage would have been less severe (IPRED, 2009). Yet, adherence to the 2010 building codes has been very low (Agency for Research and Development, Ministry of Public Works, interview, 2013). A key factor in this is that a very limited number of authorities have endorsed the 2010 building codes (Agency for Research and Development, Ministry of Public Works, interview, 2013). The 2002 law set the district-level responsible for settlements (Agency for Research and Development, Ministry of Public Works, interview, 2013). With over 450 cities and districts in Indonesia, achieving nationwide enactment is a significant challenge.

There is differential degrees of implementation of disaster risk avoidance strategies, such as retrofitting and reconstruction, across Indonesia. This has resulted in notable reductions in the vulnerability of communities to disasters in some areas and minimal changes in other areas. Improved reconstruction following the earthquakes in Yogyakarta 2006 and West Sumatra 2009 has reduced disaster risk in these areas. The presence of influential, high capacity institutions in these areas, such as UGM in Yogyakarta, has been essential to providing practical solutions to facilitating improved reconstruction (UGM, interview, 2013). This was achieved by developing construction methods which utilized local materials and local skills that provided a stronger resistance to earthquake loads.

There is substantial variation in the extent and quality of disaster risk infrastructure, such as evacuation routes and signage, in different areas in Indonesia. Institutional capacity and awareness of the role of disaster risk infrastructure have been built up in areas that have experienced recent major or recurring disasters, e.g. Mount Merapi in Yogyakarta (Centre for Volcanology and Geological Hazard Mitigation, interview, 2013). In other areas, lower institutional capacity coupled with DRR being a lower political and public priority have led to limited investments in disaster risk infrastructure (Indonesian Institute of Sciences LIPI, interview, 2013).

\subsection{Disaster risk alleviation}

Disaster risk alleviation usually involves implementing physical, technical, non-structural and procedural measures for the management of natural systems such as rivers or volcanos. The implementation of these measures can be mainstreamed through development planning.

The management of natural systems is a key mechanism to reduce the likelihood of a natural hazard occurring. An example is the reduction of flood probabilities through putting in place flood retention basins. In many cases however, the functioning of such measures has been compromised by a lack of maintenance. In Jakarta, poor maintenance of flood retention basins together with unregulated construction mean that these now operate at $30 \%$ of their original capacity. This driver of disaster risk has resulted in greater flood damage in the city - among other drivers like increased exposure due to uncontrolled development by the river banks and in- 
creased upstream run off. The lack of maintenance can be partly attributed to poor management and coordination (UNESCO Jakarta, interview, 2013). The BKSP (Greater Jakarta Coordination Board) is tasked with coordinating the provincial, four municipality and three district-level authorities in the Jakarta area. This institution has very limited authority and struggles to coordinate constituent authorities, which impacts on decision making across these jurisdictions (Sagala et al., 2013).

With respect to the mainstreaming into development planning, DRR has been set as a priority of the National MediumTerm Development Plan 2010-2014. Furthermore, it has been set as a priority in the medium-term development plans in provinces such as West Sumatra and Yogyakarta; though this is not the case in the majority of provinces. Provinces that do not have this policy precedent in place have reduced activity in DRR, including disaster risk avoidance (BPBD special province of Yogyakarta, interview, 2013; provincial BPBD West Sumatra, interview, 2013).

\subsection{Disaster risk governance}

Disaster risk governance has to do with the institutional, legal and economic contexts in which decisions about risks are taken and implemented. These parameters pertain to each of the 3As (awareness, avoidance and alleviation).

Authority for implementation of DRR has been decentralized to the provincial and district-level BPBDs, however the capacity required for implementation has not. This is partly because BNPB has been hesitant to give greater responsibility to the BPBDs (Indonesian Institute of Sciences LIPI, interview, 2013), which is evident from e.g. the fact that BNPB has been slow to develop a policy document outlining the roles and responsibilities of the actors in disaster risk management (AusAID, interview, 2013). The focus of the BPBDs so far remains on emergency response (instead of DRR), and this narrow focus has constrained their capacity as well as funding base. BPBD staff usually have limited or no experience in DRR, while attracting competent staff is difficult for various reasons. Many government staff do not want to work for BPBD as it is a newly established and under-resourced agency (BPBD Special Province of Yogyakarta, interview, 2013). Moreover, relatively low government salaries (particularly at district level) mean that staff are attracted by competitive salaries in the private sector. Furthermore, as noted by UNDP (2010), the high levels of staff rotation at lower levels present an obstacle to develop and retain capacity. This creates challenges in staff continuity and, therefore, in building up sustained DRR capacity (Centre for Volcanology and Geological Hazard Mitigation, interview, 2013). The strength of leadership is a deciding factor in the BPBDs' ability to coordinate and advocate DRR (Humanitarian Forum Indonesia, interview, 2013). However, the heads of BPBDs are not always chosen on the merit of experience or education, but out of political nepotism (Agency for Research and
Development, Ministry of Public Works, interview, 2013). In some provinces, the presence of strong NGOs, CSOs and MSPs has played a key role in building capacity and advocating BPBDs' involvement in DRR. As an example, in West Sumatra, the strong relationship between the NGO KOGAMI and provincial and district-level BPBDs has significantly enhanced the capacity of these agencies (FIELD Indonesia Foundation West Sumatra, interview, 2013).

Disconnections in DRR policies at the different levels of authority present another challenge in implementing decentralized DRR. The recommended approach of having in place a strategic and operation plan that has been adopted at national level, has not been fully implemented at the provincial level - with many provinces lacking either the strategic or operational plan (AusAID, interview, 2013). At this level, policy development is very much top-down in nature with limited input from the districts. This stems from the often poor relations between provincial and district levels. The MUSRENBANG-PROV Law (25/2004) is a Multi Stakeholder Consultation Forum for Development Planning and is the principal instrument for public consultation. It aims to reach collective consensus, identifying and prioritizing public development policies (USAID, 2007). Challenges it faces include the ability of DRR advocates to influence planning. In West Sumatra, there was very limited consultation with the provincial MSP in developing the 3-year operation plan (FIELD Indonesia Foundation West Sumatra, interview, 2013). At the district level, the ratification of the Disaster Management Law of 2007 (see Supplementary Material A) has been slow, and it is not known exactly which districts have and have not ratified the law (provincial BPBD West Sumatra, interview, 2013). As at other levels, limited consultation with NGOs, CSOs and communities has resulted in limited cross-party ownership of DRR policy (FIELD Indonesia Foundation West Sumatra, interview, 2013).

Though funding for DRR has increased at the national level, funding is insufficient at provincial and district levels. Darwanto (2012) found that only 3 of 11 provinces surveyed had spending on DRR conforming to the international standard of $1-2 \%$ of the total local government expenditure. Funding for the provincial and district level BPBDs is constrained for the following reasons. BPBDs lack credibility in comparison with larger, pre-existing government departments at the provincial and district levels. Consequently, members of parliament are much more likely to financially support these departments over the BPBDs. In West Sumatra for example, only half the budget requested from provincial government was granted (provincial BPBD West Sumatra, interview, 2013). Moreover, in Padang City, the budget from the district government is not allocated based on needs, but is equally allocated to each department (District BPBD Padang City, interview, 2013). Given this context, many BPBDs are financially dependent on BNPB to secure the required funding. Some level of fiscal support from national to local levels can be useful in supporting key strategies, however the level 
of reliance in Indonesia is not favourable. Considering the budget of BPBD Padang City, $3 \%$ is from district APBD budget, $0.5 \%$ is from provincial government and the vast majority $(96.5 \%)$ is from BNPB for tsunami preparedness programmes (District BPBD Padang City, interview, 2013). BNPB funds are often in the form of open ended, on-call budgets intended for emergency response and rehabilitation, and thus are a limited source of finance for DRR. This arrangement further limits the availability of funds for DRR (as it focuses on the stages prior to a disaster event). In West Sumatra, FIELD Indonesia Foundation West Sumatra (interview) estimated that only $10 \%$ of the BPBD's budget is allocated to DRR, with the majority going to emergency response, reconstruction and rehabilitation. As for BPBDs, financing is also a key constraint for MSPs at all levels. There are similar funding challenges with MSPS, e.g. PLANAS PRB relies almost entirely on "in kind" funding from its members (PLANAS PRB, interview, 2013). This makes the day-to-day running of this MSP particularly challenging. PLANAS's limited financial means have, furthermore, resulted in PLANAS PRB being unable to assist regional MSPs (PLANAS PRB, interview, 2013).

In addition to the challenges on funding volume and sources, the management of DRR funds allocated is an issue. There are no guidelines on reporting by BPBDs on funds allocated from BNPB (Indonesian Institute of Sciences LIPI, interview, 2013). There has been limited knowledge transfer in financial planning from national levels to those below. Funds are often given without sufficient planning and BPBDs lack capacity to effectively manage funding they receive (provincial BPBD West Sumatra, interview, 2013; $\mathrm{BNPB}^{1}$, interview, 2013). The lack of a budget tracking code in Indonesia prevents accurate analysis of spending on DRR (AusAID, interview, 2013).

Lastly, corruption remains a key challenge. Using the World Bank Worldwide Governance Indicators (WGI) as a criterion, corruption in Indonesia has not reduced despite the implementation of decentralization (Kaufmann et al., 2013). Corruption is particularly prevalent in public procurement, as reported in the post-2004 tsunami reconstruction in Aceh (Scott and Tarazona, 2011). It has also been an issue in relocation from flood prone areas in Jakarta (UNESCO Jakarta, interview, 2013).

\subsection{Good practice characteristics of decentralization}

It was considered important to deduce good practice characteristics of decentralization to facilitate the gap analysis. These good practice characteristics discussed in this section form the view of the ideal state for good governance.

Decentralized government requires careful planning, which should be underpinned by the principle of subsidiarity (whereby authority is devolved to the lowest level appropriate) (UNDP, 2004). Capacity building and empowerment of lower levels is needed to implement DRR in line with the authority that now exists at these levels (Djalante et al., 2011; Indonesian Institute of Sciences LIPI, interview, 2013). Given the cross sectoral nature of DRR, cross party ownership in governmental and non-governmental entities is needed to mainstream DRR across all sectors and create the participatory framework required for decentralization (Indonesian Institute of Sciences LIPI, interview, 2013; UNESCO Jakarta, interview, 2013).

Connected policies, both vertically and horizontally in levels of administration, are needed to facilitate the multi-level governance processes required (Datta et al., 2011). The clear delineation of roles and responsibilities in a nested support structure from national to local levels is an important precondition of decentralization (UNESCO Jakarta, interview, 2013). This must be accompanied by regulated risk-based financing from the appropriate level of government, so that DRR can be implemented at the decentralized levels (AusAID, interview, 2013).

\subsection{Identified barriers for decentralized DRR in Indonesia}

Key barriers to the implementation of decentralized DRR in Indonesia were deduced through the gap analysis by comparing the current state with the deduced good practice characteristics (ideal state). The barriers presented below are obstacles to the realization of decentralized DRR in Indonesia.

First, capacity gaps at lower levels present a barrier for decentralization in relation to DRR. The focus on emergency response in the BPBDs means that awareness and engagement of these agencies in DRR is low, and therefore it is not prioritised. This amplifies difficulties in mainstreaming DRR in Indonesia as many lower level authorities believe DRR is not their responsibility. Local levels often do not have the capacity required to recognise their own needs and are thus ill-equipped to seek the appropriate support from higher level authorities. Furthermore, limited (individual) capacity among BPBD staff and high staff turnover mean that creating a sustained knowledge base on DRR is difficult at lower levels. In some instances, like curriculum development and risk assessment, capacity has not been decentralized with decision making authority. This concurs with findings by Scott and Tarazona (2011) and also with Djalante et al. (2011) particularly on the capacity challenges at lower levels.

Low levels of compliance with legislation is another barrier, which is indicative of the challenge facing decentralized DRR from a prioritization perspective. In this study, poor compliance was noted in relation to the following parameters: spatial planning, building codes and retrofitting and reconstruction. The slow enactment of instruments such as spatial planning at the sub-national level hinders the creation of a decentralized policy context needed for effective DRR.

Disconnected policies at the different levels are a third barrier for decentralized DRR. Many provinces and districts lack a strategic and/or operation plan, thus creating a policy dis- 
connect with the national level. Furthermore, the top-down nature of provincial level policy development is not building ownership from the districts, which reduces the effectiveness of implementation. At district level, there is limited DRR policy in place to mobilise the substantial power that now exists there. This is demonstrated by the small number of districts that have ratified the Disaster Management Law. Also, the lack of consultation with non-governmental actors at this level has resulted in low cross-party ownership of DRR policy. Sutmeller and Setiono (2011) also highlight these disconnects as key challenges in their review of policy formation in decentralized government in Indonesia.

Issues of coordination and communication also hinder the implementation of decentralized DRR. The focus on implementation by BNPB and provincial BPBDs means they are not sufficiently active in coordination and advocacy for DRR at their respective level of administration. Some authorities at various levels have been active in DRR, however this is not coordinated by BNPB. Misalignments in authority and funding also create a coordination challenge. District BPBDs are for a majority reliant on funding from BNPB and not local government, thus creating a coordination disconnect with local government and provincial BPBDs. Poor coordination and collaboration between MSPs prevents knowledge transfer and limits their involvement in DRR governance. This is a barrier to creating the participatory governance structure that is required for decentralized DRR.

A final barrier is the financing of decentralized DRR. Local governments are often reluctant to fund BPBDs, as these have only recently been established and lack the credibility of longer existing agencies. Finance sourcing is a further issue with the on-call budgets for BPBDs being directed to emergency response. Other relevant issues are the lack of reporting mechanisms, budget tracking, spend guidelines and financial planning capacity at lower levels. Scott and Tarazona (2011) observed similar funding challenges in South Africa, Mozambique and Colombia where earmarked DRR funding was redirected to emergency response and other areas.

\section{Discussion}

\subsection{A reflection of the current state of decentralized DRR in Indonesia and barriers identified}

The results of this study have shown that Indonesia has made significant progress to a decentralized governance of DRR though key barriers remain.

At national levels legislation has been implemented to facilitate decentralization however this has not followed through to lower levels, on a consistent basis. It has been seen from the current state in Indonesia that a legislative precedent is required. This legislation must then be actioned in practice to facilitate decentralization of DRR.
The delineation of roles, responsibility and authority is critical to achieve effective decentralization with multiple levels of administration now governing a particular geographic area. The lack of clarity in this area between BNPB and newly established BPBDs poses a barrier to implementation.

As with all change, some parties are reluctant to adopt to new practices. This can be seen with the continued focus on emergency response at lower levels and a hesitancy to relinquish delivery capability at higher levels. Decentralization of capability and resourcing, within a defined governance support structure, is a key criterion of the change management required.

There is evidence for the possibilities and opportunities that decentralization offers in the Indonesian case study. The mainstreaming of local DRR content into school curricula in Aceh, Padang and Yogyakarta and the contribution of MSPs to DRR planning and delivery are good examples of this. Empowerment of local levels and engagement of MSPs and communities have been key to realising these opportunities in Indonesia.

\subsection{A reflection of decentralization in other developing countries in other sectors}

Decentralization has been undertaken for the governance of a range of sectors in many countries (Faguet, 2011). However, results from the ground on decentralization have been mixed, particularly in developing states. Treisman (2010) has noted, for example, that decentralized governance may lead to reduced efficiency, poorer policy quality and smaller economies of scale in the provision of public sector services. Given these results, it can be argued that the barriers identified in this paper are not unique for DRR. As such, it is worthwhile to consider the barriers for decentralized DRR alongside those observed for decentralization in other developing countries in other sectors. Without attempting to be exhaustive, some parallels are drawn between different barriers (or enablers) in this sub-section.

Riker (1964) observed that a balance between centripetal forces (the centre capturing the powers of the lower jurisdictions) and fissiparous forces (common pool problems at the lower levels) is required for effective decentralized governance. In Argentina, the decentralized governance framework has not achieved this balance with powerful subnational levels succeeding in drawing large bailouts from national levels due to the high levels of influence they exert on national government (Faguet, 2011). A level of supervision from higher levels is required to ensure consistency and realise best practice (although excessive control will negate the benefits of decentralization). The parallel with the case of DRR in Indonesia is that the movement toward decentralization has biased the power of the district level over the provincial level. 
The decentralization of health services in Pakistan provides further evidence of barriers, or rather enablers, for implementation. In a study of healthcare units in 17 districts, the district-level officials that engaged the most with their decentralized authority had stronger decision making capacities and were held more accountable to local representatives (Bosser et al., 2008). As noted in the case of DRR in Indonesia, the role of leadership at the given level of authority is critical to realising effective decentralized DRR.

As observed in this study on decentralization of DRR in Indonesia, poor coordination between the central and provincial levels in Trinidad was reported by Seepersad and Douglas (2002) as a key barrier to decentralization of agriculture. While a focus on coordination and clear delineation of roles of the different levels of authority was found to be a key enabler in the decentralization of agriculture in Venezuela (Savioff and Lindarte, 2002).

A lack of fiscal sustainability was identified as a key barrier for decentralized DRR in Indonesia, with regional organizations largely reliant on national level funding. This phenomenon of significant vertical transfers has also been observed in several Latin American states and prompted the second generation of decentralization reforms aimed at realising fiscal sustainability (Faguet, 2011). The improved management of subnational finances led to a more stable national level fiscal environment in Argentina, Brazil and Mexico (Faguet, 2011; Diaz-Cayeros et al., 2014).

In Argentina, the decentralized governance framework has facilitated subnational actors abusing the existing system for their own personal gains, weakening political competition and the rule of law (Ardanaz et al., 2014). Parallels may be drawn here with decentralization of DRR in Indonesia in that corruption levels in Indonesia have not reduced despite the decentralization that has taken place.

\section{Conclusions}

DRR is particularly important in developing states, because these states are generally more vulnerable to natural hazards than developed states. While a similar (average) number of people may be exposed to natural hazards in developing and developed states (11 and $15 \%$, respectively), the average number of fatalities each year is very different (53 and $1 \%$, respectively) (Peduzzi, 2006). To improve the governance of DRR, international policy frameworks, such as the Sendai Framework, have called for decentralization of decision making authority to lower levels. Key expectations of decentralized DRR include increased equity, accountability, effectiveness and responsiveness as well as reduced abuses of power (Faguet, 2011). Such expectations are particularly relevant in developing states of the geographic scale and cultural diversity of Indonesia.

The Indonesian government's commitment to the implementation of decentralized DRR is evident from the insti- tutional restructuring and the updated legal and financing system. As a result, considerable progress has been made in reaching the expectations of decentralization, as demonstrated in the case study; however, a number of different barriers prevent the full potential of decentralized DRR from being realized. Key barriers to implementation in Indonesia include: capacity gaps at lower institutional levels, low compliance with legislation, disconnected policies, issues in communication and coordination, and inadequate resourcing.

Although decentralization in relation to DRR does present challenges, the potential benefits do outweigh the implementation burden and costs. It should also be noted that many of the challenges are not unique to DRR, and similar challenges have been observed for decentralization in other public sectors. Decentralization (in general) is a complex process that requires enabling conditions to be in place before it can be successfully implemented. These include capacity building at lower levels, a strong intergovernmental framework, clear rules of implementation and local level financial autonomy.

\section{Data availability}

The underlying research data of interview notes is available publicly in the UNESCO-IHE catalogue at the link below. http://unesco-ihe.worldcat.org/oclc/858366241. 


\section{Appendix A}

Table A1. Acronyms.

\begin{tabular}{ll}
\hline ASEAN & Association of Southeast Asian Nations \\
AusAID & Australian Agency for International Development \\
BMKG & Indonesian Agency for Meteorological, Climatological and Geophysics \\
BNPB & Indonesian National Disaster Management Agency \\
BPBD DKI Jakarta & Jakarta Provincial Disaster Management Agency \\
BPBD Padang City & Padang City District Disaster Management Agency \\
BPBD West Sumatra & West Sumatra Provincial Disaster Management Agency \\
BPBD Yogyakarta & Yogyakarta Provincial Disaster Management Agency \\
CVGHM & Centre for Volcanology and Geological Hazard Mitigation \\
HFI & Humanitarian Forum Indonesia \\
KOGAMI & Tsunami Alert Community West Sumatra \\
LIPI & Indonesian Institute of Sciences \\
MPBI & Indonesian Society for Disaster Management \\
PLANAS PRB & Indonesian National Platform for DRR \\
UNDP & United Nations Development Programme \\
UNESCO & United Nations Educational, Scientific and Cultural Organization \\
UNDP & United Nations Development Programme \\
UNICEF & United Nations Children's Fund \\
UGM & Gadjah Mada University, Yogyakarta \\
\hline
\end{tabular}




\section{The Supplement related to this article is available online at doi:10.5194/nhess-16-2145-2016-supplement.}

Acknowledgements. The authors would like to thank the UNESCO Jakarta office for being the focal point of this study on the ground in Indonesia, and in particular to Ardito Kodijat for the sharing of his great experience and networks in DRR in the country. We are most grateful to all those who gave their time for interview and shared their insight into DRR in Indonesia and in developing states in general. We acknowledge the support within the Memorandum of Understanding between UNESCO-IHE and the Ministry of Infrastructure and Environment (Assistance for Disaster Risk Management project).

Edited by: M. Keiler

Reviewed by: R. Djalante and one anonymous referee

\section{References}

Agency for Research and Development, Ministry of Public Works, interview, 24 June 2013.

Ardanaz, M., Leiras M., and Tommasi, M.: The politics of federalism in Argentina: Implications for governance and accountability, World Develop., 53, 26-45, 2014.

ASEAN Coordinating Centre for Humanitarian Assistance, interview, 25 June 2013.

Ashley, R., Blanksby, J., Maguire, T., and Leahy, T.: Frameworks for adapting to flood risk: experiences from the EU's flood resilient city project, in: Proceedings of the 1st IAHR European Congress, Sheffield, UK, 4-6 May 2011.

AusAID Australian Agency for International Development, interview, 25 June 2013.

AusAID:

http://dfat.gov.au/aid/topics/

investment-priorities/building-resilience/

disaster-risk-reduction-prevention-preparedness/Pages/

disaster-risk-reduction-prevention-and-preparedness.aspx,

last access 11 July 2016.

Batica, J.: Methodology for flood resilience assessment in urban environments and mitigation strategy development, Doctoral dissertation, Université Nice Sophia Antipolis, 2005.

Bollin, C.: Community-based disaster risk management: Experience gained in Central America, Deutsche Gesellschaft für Technische Zusammenarbeit (GTZ), Eschborn, Germany, 13-18, 2003.

Bosser, T., Michell, A., Mian, N., and Janjua, M.: District-level decision space analysis in Pakistan, Pakistan Initiative for Mothers and Newborns (PAIMAN), Islamabad, Pakistan, 11-25, 2008.

$\mathrm{BNPB}^{1}$, interview, 13 June 2013.

$\mathrm{BNPB}^{2}$, interview, 5 July 2013.

BPBD Special Province of Yogyakarta, interview, 13 June 2013.

Centre for Volcanology and Geological Hazard Mitigation, interview, 10 June 2013.

COE-DMHA (Centre of Excellence for Disaster Management and Humanitarian Assistance), Country Disaster Response Handbook: Indonesia, US Government Printing House,
Tripler, USA, available at: http://reliefweb.int/report/indonesia/ country-disaster-response-handbook-indonesia, 2011.

Datta, A., Jones, H., Febriany, V., Harris, D., Dewi, R. K., Wild, L., and Young, J.: The political economy of policy-making in Indonesia, Overseas Development Institute (ODI), London, UK, 2011.

Dharma, A.: Indonesian basic education curriculum: Current content and reform, Presented in Roundtable Discussion in Retrac Governing Board Meeting at Institut Aminuddin Baki, Genting Highland, Malaysia, 27 August 2008, Malaysia, 2008.

Diaz-Cayeros, A., Magaloni, B., and Ruiz-Euler, A.: Traditional governance, citizen engagement, and local public goods: Evidence from Mexico, World Develop., 53, 80-93, 2014.

District BPBD Padang City, West Sumatra, interview, 27 June 2013.

Djalante, R.: Review Article: "Adaptive governance and resilience: the role of multi-stakeholder platforms in disaster risk reduction", Nat. Hazards Earth Syst. Sci., 12, 2923-2942, doi:10.5194/nhess-12-2923-2012, 2012.

Djalante, R., Holley, C., and Thomalla, F.: Adaptive Governance and Managing Resilience to Natural Hazards, Int. J. Disaster Risk Sci., 2, 1-14, 2011.

Faguet, J. P.: Decentralisation and Governance, World Develop., 53, 2-13, 2011.

FIELD Indonesia Foundation West Sumatra, interview, 28 June 2013.

Hooghe, L. and Marks, G.: Types of multi-level governance, European integration online papers (EIoP), 5, 2001.

Humanitarian Forum Indonesia, interview, 26 June 2013.

IFRC (International Federation of Red Cross and Red Crescent Societies): Public Awareness and Public Education for Disaster Risk Reduction: A Guide, Geneva, Switzerland, 40-57, 2011.

Indonesia: National Disaster Management Agency Regulation, Jakarta, Indonesia, 20-24, 2008.

Indonesian Institute of Sciences LIPI, interview, 13 June 2013.

IOM (International Organisation for Migration): Disaster Risk Reduction, Climate Change Adaption and Environmental Migration, IOM, Geneva, Switzerland, p. 10, 2009.

IPCC (Intergovernmental Panel on Climate Change): Summary for Policymakers - Managing the Risks of Extreme Events and Disasters to Advance Climate Change Adaptation, in: A Special Report of Working Groups I and II of the Intergovernmental Panel on Climate Change, Cambridge University Press, Cambridge, UK, and New York, USA, 1-19, 2012.

IPRED (International Platform for Reducing Earthquake Disasters): Brief Report on the Building Investigation after Earthquake Disaster in West Java Area, UNESCO, Paris, France, available at: http://www.ipred-iisee.org (last access: 19 September 2016), 2009.

Kaufmann, D., Kraay, A., and Mastruzzi, M.: http://info.worldbank. org/governance/wgi/index.aspx\#home, last access 9 August 2015.

Kurniadi, B.: Yogyakarta in Decentralized Indonesia: Integrating Traditional Institution in Democratic Transitions, Jurnal Ilmu Sosial dan Ilmu Politik (JSP), 13, 191-192, 2009.

Lassa, J. A.: Institutional Vulnerability and Governance of Disaster Risk Reduction: Macro, Meso and Micro Scale Assessment, $\mathrm{PhD}$ thesis, Hohen Landwirtschaftlichen Faculty, Rheinischen Friedrich-Wilhelms University, Bonn, Germany, 2010. 
Peduzzi, P.: The Disaster Risk Index: Overview of a quantitative approach. In: Measuring Vulnerability to Natural Hazards - Towards Disaster Resilient Societies, edited by: Birkmann, J., United Nations University Press, Tokyo, Japan, 171-181, 2006.

PLANAS PRB, interview, 4 July 2013.

Provincial BPBD West Sumatra, interview, 28 June 2013.

Renn, O., Klinke, A., and van Asselt, M.: Coping with complexity, uncertainty and ambiguity in risk governance: a synthesis, Ambio, 40, 231-246, 2011.

Riker, W. H.: Federalism: Origin, Operation, Significance, Little Brown, Boston, USA, p. 6, 1964.

Sagala, S., Lassa, J., Yasaditama, H., and Delik, H.: The Evolution of Risk and Vulnerability in Greater Jakarta: Contesting Government Policy in Dealing with a Megacity's Exposure to Flooding, An Academic Response to Jakarta Floods in January 2013, Institute of Resource Governance and Social Change (IRGSC), Jakarta, Indonesia, 13-14, 2013.

Savioff, M. and Lindarte, E.: Reforming National Extension: The Recent Experience of Venezuela, Unpublished Extension Case Study, World Bank, Washington, D.C., USA, 3-5, 2002.

Scott, Z. and Tarazona, M.: Study on Disaster Risk Reduction, Decentralisation and Political Economy, in: Global Assessment Report on Disaster Risk Reduction Revealing Risk Redefining Development, UNISDR, Geneva, Switzerland, 17-29, 2011.

Seepersad, J. and Douglas, V.: Decentralization of the Extension Services in Trinidad. Unpublished Extension Case Study, The World Bank, Washington, D.C., USA, 2002.

Sutmeller, P. and Setiono, I.: Diagnostic on Evidence-based Policy Formulation under Decentralisation, AusAID, Jakarta, Indonesia, 2011.

Treisman, D.: The Architecture of Government: Rethinking Political Decentralization, Public Choice, 142, 257-259, 2010.

UGM, Yogyakarta, interview, 30 June 2013.

UNDP: Decentralised Governance for Development: A Combined Practice Note on Decentralisation, Local Governance and Urban/Rural Development, UNDP, New York, USA, 3-9, 2004.

UNDP: A Global Review: UNDP Support to Institutional and Legislative Systems for Disaster Risk Management, New York, UNDP, 4-10, 2007.
UNDP: The Missing Link: The Province and Its Role in Indonesia's Decentralisation, UNDP, Jakarta, Indonesia, 10-22, 2009.

UNDP: Disaster Risk Reduction, Governance \& Mainstreaming, New York, UNDP, 1-3, 2010.

UNDP Jakarta, interview, 6 July 2013.

UNESCAP: What is Good Governance? UNESCAP, Bangkok, Thailand, 1-4, 2009.

UNESCO Jakarta, interview, 5 July 2013.

UNISDR: Hyogo framework for action 2005-2015: building the resilience of nations and communities to disasters, Extract from the final report of the World Conference on Disaster Reduction, A/CONF, 206/6, 2005.

UNISDR: Building a Local Government Alliance for DRR 'The Incheon Declaration' Summary from 11-13 August 2009 Conference, UNISDR, Incheon, South Korea, 9-11, 2009.

UNISDR: Local Governments and Disaster Risk Reduction, UNISDR, Geneva, Switzerland, 1-7 and 48-52, 2010.

UNISDR: Chapter 7 Reforming Risk Governance, Global Assessment Report on Disaster Risk Reduction Revealing Risk Redefining Development, UNISDR, Geneva, Switzerland, 136146, 2011.

UNISDR: Sendai Framework for Disaster Risk Reduction 2015-2030, http://www.wcdrr.org/uploads/Sendai_Framework_ for_Disaster_Risk_Reduction_2015-2030.pdf, last access: 9 August 2015.

USAID: Musrenbang as a Key Driver in Effective Participatory Budgeting: Key Issues and Perspectives for Improvements, USAID, Jakarta, 2-5, 2007.

Walker, G., Tweed, F., and Whittle, R.: A framework for profiling the characteristics of risk governance in natural hazard contexts, Nat. Hazards Earth Syst. Sci., 14, 155-164, doi:10.5194/nhess14-155-2014, 2014.

Wulan Mei, E. T., Lavigne, F., Picquout, A., de Bélizal, E., Brunstein, D., Grancher, D., Sartohadi, J., Cholik, N., and Vidal, C.: Lessons learned from the 2010 evacuations at Merapi volcano, J. Volcanol. Geoth. Res., 261, 348-365, 2013. 